\title{
Addictive agents and intracranial stimulation: Morphine and thresholds for positive intracranial reinforcement
}

\author{
KIM L. KELLEY and LARRY D. REID \\ Bradley University, Peoria, Illinois 61606
}

\begin{abstract}
Rats were fixed with chronically indwelling bipolar electrodes. Subsequently, they pressed for direct electrical stimulation of the lateral hypothalamus. Then thresholds for the positive intracranial reinforcement were measured daily for 20 days while rats were under the influence of morphine injections $(10 \mathrm{mg} / \mathrm{kg}$ given $3.5 \mathrm{~h}$ prior to testing). Morphine reduced thresholds after the first few days of dosing and the reductions, once seen, did not wane with further dosing. Furthermore, thresholds were reduced by a $10-\mathrm{mg} / \mathrm{kg}$ dose of morphine following a regimen of dosing with morphine that produced physical dependence. It was concluded that morphine reduced thresholds for positive intracranial reinforcement and this capability was not changed by assimilation of relatively large quantities of morphine, that is, the effect did not show tolerance.
\end{abstract}

Under certain circumstances, morphine injections accelerate pressing for hypothalamic intracranial stimulation (ICS) (Adams, Lorens, \& Mitchell, 1972; Bush, Bush, Miller, \& Reid, 1976; Pert, 1975). The increased pressing is not due to a general nonspecific facilitation of behavior but to a specific effect on pressing for ICS (Farber \& Reid, 1976; Koob, Spector, \& Meyerhoff, 1975; Lorens \& Mitchell, 1973). Furthermore, at times of greatest acceleration of pressing, the state elicited by the morphine injections is positive affect (Rossi \& Reid, 1976). From what is known about intracranial reinforcement (Olds, 1969) and from research with morphine and pressing for ICS, it has been suggested that morphine's positively reinforcing characteristics are related to its action on the tissue of positive ICS. Furthermore, the positive reinforcement of morphine may be critical to the maintenance of the behavior of assimilation of morphine (references cited above; McAuliffe \& Gordon, 1974; work following Weeks, 1962). The conclusion that morphine increases activity of the tissue of ICS and thereby leads to increased pressing would be strengthened considerably if it were demonstrated that thresholds for intracranial reinforcement were lowered by morphine. Recently, it has been demonstrated that morphine decreased thresholds of intracranial reinforcement (Esposito \& Kornetsky, 1977; Marcus \& Kornetsky, 1974).

This study was supported by Grant DA01049 from the National Institute of Drug Abuse, DHEW. The paper was derived from a Master's thesis of the first author supervised by the second author. K. Kelley is now at Vanderbilt University. L. Reid is now at the Department of Psychology, Rensselaer Polytechnic Institute, Troy, New York 12181. We thank Professor Mills, Tufts University for demonstrating his procedures to us.
If the accelerated pressing for ICS and concomitant lowering of thresholds of intracranial reinforcement are reflecting processes critical to sustaining the enduring behavior related to assimilation of morphine, then it follows that the accelerated pressing and lowered thresholds should be seen after considerable morphine assimilation. Esposito and Kornetsky did show that thresholds of ICS were decreased across about 34 days of daily dosing. Threshold measures have some advantage in potential precision compared to pressing rates as measures (Esposito \& Kornetsky, 1977). This study addresses issues similar to those addressed by Esposito and Kornetsky. This study and their study report very similar results and both lead to similar conclusions. The methods used, however, were somewhat different across the two studies, thereby strengthening the derived conclusions.

\section{METHOD}

\section{Subjects}

Five adult (250 to $300 \mathrm{~g})$ male Holtzman rats served. Each of the rats was fixed, using standard procedures, with a chronically indwelling bipolar electrode for ICS of the lateral hypothalamus. The commercially available electrodes (Plastic Products) were two stainless steel wires wrapped around each other and insulated except at the cross section of their tips. Histological analyses of the rats' brains, subsequent to behavioral testing, verified that all electrode tips were in the lateral hypothalamic area activating an area including the medial forebrain bundle, Forel's fields, and zona incerta. Toward the end of testing, one rat given morphine was lost. Consequently, some of the analyses have the data of only four rats.

\section{Apparatus}

The experimental chamber was a clear Plexiglas box $(24 \times 30 \times 35 \mathrm{~cm})$. It was fitted with a lever which extended through one wall of the box. Depression of the lever yielded ICS of a selected intensity and advanced a predetermining counter. ICS was delivered by way of light flexible leads attached to a 
slip ring, allowing rats' unhampered movement. ICS was $60-\mathrm{Hz}$ sine waves of $.25 \mathrm{sec}$ and of varying intensities, but always less than 32 microA. Oscilloscopes measured the intensities of ICS to an accuracy of 1 microA.

\section{Procedure}

After recovery from surgeries, rats were trained to leverpress for ICS. During daily sessions, rats' training was continued in order to establish stabilized performance on fixed-ration (FR) schedules of reinforcement. Their training continued until pressing was sustained by a schedule of leverpresses to ICS of either $20: 1$ or $25: 1$ (FR 20:1 or FR $25: 1$ ). Three of five rats performed consistently with an FR 20:1 schedule and two rats with an FR 25:1 schedule. Once a rat's ratio schedule was selected, it was used throughout the remainder of the procedures. The intensity of ICS of these FR schedules was 30 microA for all rats across all sessions.

The FR schedules produced the characteristic postreinforcement pauses (PRPs), allowing us to use Huston and Mills' (1971) method for measuring thresholds of intracranial reinforcement. Their method uses the PRP as an index of rats' changing performance. Briefly, the method involves maintaining rats' performance on the FR schedule for 30-microA ICS while giving ICS of varying intensities with each leverpress. With zero intensity of ICS for every leverpress, rats perform as if they were on an FR schedule, that is, they show PRPs of substantial duration. With 30 microA of ICS for every leverpress, rats perform as if they were being reinforced for each leverpress (which, of course, they were) and show no PRPs. When intensities for each leverpress are between 0 and 30 microA, PRPs disappear. The intensity given for each leverpress that eliminates $50 \%$ of the PRPs is said to be the threshold for intracranial reinforcement.

The definition of a PRP is the one given by Huston and Mills (1971). To determine a PRP, Huston and Mills first measured the longest interval between individual leverpresses beginning with the last press of the FR cycle and ending with the fourth press of the new FR schedule. This measure was then compared to interresponse intervals between the remaining presses in the FR chain (the time between individual presses after the fourth press in the FR cycle and the completion of the FR schedule). If the longest measured interval following a 30 -microA reinforcer was greater than the mean of the interresponse interval plus three standard deviations from the mean of the measured interresponse interval, then it was called a PRP.

Huston and Mills' (1971) apparatus allowed them to measure the intervals between presses directly. Our recording apparatus did not allow such precision. We took the time elapsed between the FR reinforcement and the fourth press in the new FR cycle and the time between the fourth press and the last leverpress and calculated means. Using 15 cycles for a given intensity programmed for each leverpress, we calculated the mean and variance of the intervals between leverpresses by using the sample means ( 1 mean/cycle). Consequently, at the end of 15 FR chains the criterion for a PRP was determined. Using this calculated criterion, the pauses immediately following the 30 microA were categorized as either a PRP or not a PRP. Intensities of ICS with every leverpress were increased in increments until PRPs disappeared and then decreased until PRPs reappeared.

Using the method of Huston and Mills, threshold for intracranial reinforcement was measured during five consecutive daily sessions (baseline). Subsequent to baseline measurements, four of the five rats were given a daily $10-\mathrm{mg} / \mathrm{kg}$ subcutaneous injection of morphine sulfate. The other rat received an equal volume of physiological saline. During each day of a 20-day drug regimen, all rats' thresholds were determined during a session lasting about $1 \mathrm{~h}$ and beginning $3.5 \mathrm{~h}$ after injections.

Following the 20-day period, there was a 5-day schedule of three injections a day during which thresholds were not de- termined. The doses of the 1 st day's injections were $10 \mathrm{mg} / \mathrm{kg}$ of morphine for the four rats of previous morphine injections and an equal volume of saline for the other rat. For the rats of morphine, the daily doses were increased by $5 \mathrm{mg} / \mathrm{kg}$ until, by the 5 th day, they got three doses of $30 \mathrm{mg} / \mathrm{kg}$ of morphine sulfate. This regimen of dosing with morphine was designed to produce physical dependence as indexed by withdrawal symptoms.

On the day following the last injection of morphine or placebo (about $14 \mathrm{~h}$ after last injection), thresholds were again determined and were determined on each of the subsequent days, for a total of 10 daily determinations. During the last 5 days of threshold measurements, rats again received the dosing of the first 20-day period. To summarize, thresholds of reinforcement were measured prior to dosing with morphine (baseline), on 20 days after a daily dose of morphine, on days when rats were potentially experiencing withdrawal symptoms, on days just after potential withdrawal symptoms, and on days when they were again given the dose of the first 20 days of injections.

\section{RESULTS}

The results are summarized in Figure 1. The data points of Figure 1 were derived from difference scores. A difference score was obtained by subtracting mean baseline thresholds from a given day's determination. Therefore, a negative score indicates a reduction in threshold compared to baseline. Figure 1 presents mean difference scores for the four rats who received morphine during initial dosing and the three rats receiving morphine after physical dependence.

It can be seen from Figure 1 that thresholds were not reduced with the first few days of morphine injections, but were subsequently. Using $t$ tests for correlated

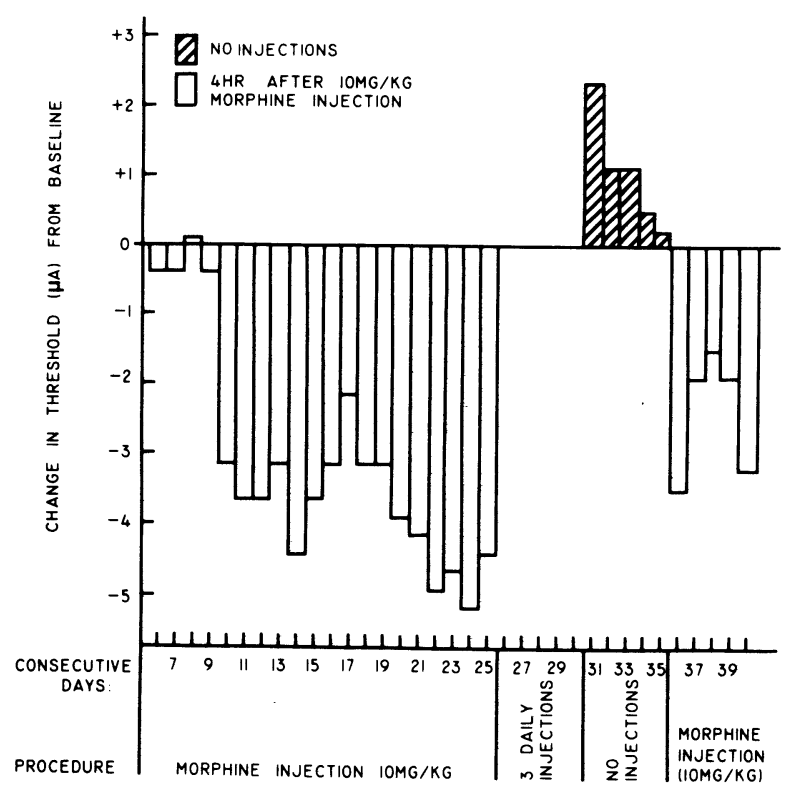

Figure 1. Mean changes in thresholds from baseline thresholds across days of the procedure. A negative score indicates a reduction in threshold. The measurements with the initial injections of $10 \mathrm{mg} / \mathrm{kg}$ involved four rats; with the second set of injections, they involved three rats. 
measures, baseline thresholds were compared to thresholds on the subsequent days. The $p$ values associated with Days 7-20 of dosing were all $\leqslant .05$, with the exception of Days 11 and 13 (ps $<.10)$.

On the 1st day of potential withdrawal, subjects' thresholds were reliably greater than their baseline scores $[\mathrm{t}(3)=3.79, \mathrm{p}<.05]$. By the 5 th day of this testing, rats' thresholds were not reliably different from baseline $[t(2)=1.0, p>.3]$. Since rats by the 5 th day were regaining the weight lost during the first days of withdrawal, we presume all withdrawal symptoms had abated. With the reintroduction of morphine, thresholds were again reduced to the level of the previous threshold reductions. The last day of the initial $10-\mathrm{mg} / \mathrm{kg} / \mathrm{day}$ dosing yielded, for the three rats that completed procedures, a mean threshold reduction of 4.2 microA. The last day of dosing of the entire procedure, for the same rats, yielded a threshold reduction of 4.3 microA compared to initial baseline. These reductions are at least two times greater than the largest reduction seen on any occasion by the control subject or during any given day of baseline of the subjects of morphine. The control subjects' threshold did not-systematically shift across the days of threshold determinations.

\section{DISCUSSION}

Prior to the test reported above, two rats were tested in a pilot study to acquaint ourselves with the method. In general, the data of those two subjects are similar to those of the data reported above. In addition, however, to tests at $4 \mathrm{~h}$ after injections, the rats of the pilot study were tested $1 \mathrm{~h}$ after $10-\mathrm{mg} / \mathrm{kg}$ injections of morphine. The method did not allow threshold determination at $1 \mathrm{~h}$ across 5 days, because the rats' behavior was so depressed that they did not sustain pressing on the FR schedule. Although, this method of Huston and Mills (1971) is somewhat independent of rate of pressing, it is definitely limited. As long as the rats will sustain pressing on the FR schedule, however, we surmise that the test is, as Huston and Mills claim, independent of rate of pressing.

The rats of Bush et al. (1976) pressed for ICS $4 \mathrm{~h}$ after a $10-\mathrm{mg} / \mathrm{kg}$ injection across 20 days. This dosing and testing regimen is the same as for the rats of this study. The rats of Bush et al. did not show accelerated pressing until the 3rd to 5 th day of dosing, but did show accelerated pressing across the remaining days of testing. Interestingly, the reduction in thresholds of intracranial reinforcement with this relatively rateindependent measure did not occur until after about 5 days of daily dosing. The reduction once seen did not attenuate across the remaining days of dosing. The remarkable concordance in results achieved with tests of barpressing and with tests of threshold determination lead to the suggestion that the two tests are reflecting similar events.

Because of the relatively rate-independent nature of the threshold measurement, we conclude that the increased thresholds seen while the rats were experiencing withdrawal symptoms reflect decreased activity in tissue of ICS. This conclusion is concordant with Stein's (1964) hypothesis that patterns of activity of aversive states inhibit patterns of potentially positive affective states (Buckwalter, Gibson, Reid, \& Porter, 1967).

After 20 days of daily injections and after 5 days of multiple injections, the rats of this study had considerable quantities of morphine (totaling $500 \mathrm{mg} / \mathrm{kg}$ across 25 days). Despite this regimen of dosing, the dose of $10 \mathrm{mg} / \mathrm{kg}$ still reduced thresholds for ICS. The one salient characteristic of addictive agents is their continuing ability to reinforce the behavior preceding their assimilation. It seems that the critical consequence for maintenance of the behavior of drug assimilation should also endure with multiple dosing and should follow the behavior it reinforces. Since the lowering of the threshold for intracranial reinforcement with morphine endures across multiple doses and most likely reflects a reinforcement process, we agree with Esposito and Kornetsky (1977) that the events we are measuring may be critical to the drug's ability to maintain its use.

\section{REFERENCES}

Adams, W. J., Lorens, S. A., \& Mitchell, C. L. Morphine and lateral hypothalamic self-stimulation in the rat. Proceedings of the Society of Experimental Biology and Medicine, 1972, 140, 770-771.

Buckwalter, M. M., Gibson, W. E., Reid, L. D., \& Porter, P. B. Combining positive and negative intracranial reinforcement. Journal of Comparative and Physiological Psychology, 1967, 64, 329-331.

Bush, H., Bush, M., Miller, A., \& Reid, L. Chronic morphine administration and hypothalamic intracranial stimulation. Physiological Psychology, 1976, 4, 79-85.

Esposito, R., \& Kornetsky, C. Morphine lowering of selfstimulation thresholds: Lack of tolerance with long-term administration. Science, 1977, 195, 189-191.

FARBER, P. D., \& ReID, L. D. Addictive agents and intracranial stimulation (ICS): Daily morphine and pressing for combinations of positive and negative ICS. Physiological Psychology, 1976, 4, 262-268.

Huston, J. P., \& Mills, A. W. Threshold of reinforcing brain stimulation. Communication in Behavioral Biology, 1971, 5, 331-340.

Koob, G. F., Spector, N. H., \& Meyerhoff, J. L. Effects of heroin on lever pressing for intracranial self-stimulation, food and water in the rat. Psychopharmacologia (Berlin), 1975, 42, 231-234.

Lorens, S. A., \& Mitchell, C. L. Influence of morphine on lateral hypothalamic self-stimulation in the rat. Psychopharmacologia (Berlin), 1973, 38, 1-13.

Marcus, R., \& Kornetsky, C. Negative and positive intracranial reinforcement thresholds: Effects of morphine. Psychopharmacologia (Berlin), 1974, 38, 1-13.

McAuliffe, W. E., \& Gordon, R. A. A test of Lindesmith's theory of addiction: The frequency of euphoria among long-term addicts. American Journal of Sociology, 1974, 70, 795-780.

Olds, J. The central nervous system and reinforcement of behavior. American Psychologist, 1969, 24, 114-132.

Pert, A. Effects of opiates on rewarding and aversive brain stimulation in the rat. Proceedings of the 37 th Annual Scientific Meeting Committee on Problems of Drug Dependence, 1975, 963-973.

Rossi, N. A., \& REID, L. D. Affective states associated with morphine injections. Physiological Psychology, 1976, 4, 269-274.

Stein, L. Reciprocal action of reward and punishment mechanisms. In R. G. Heath (Ed.), The role of pleasure in behavior. New York: Hoeber, 1964. Pp. 113-139.

WEEKS, J. R. Experimental morphine addiction: Method for automatic intravenous injections in unrestrained rats. Science, 1962, 138, 143-144.

(Received for publication June 12, 1977.) 